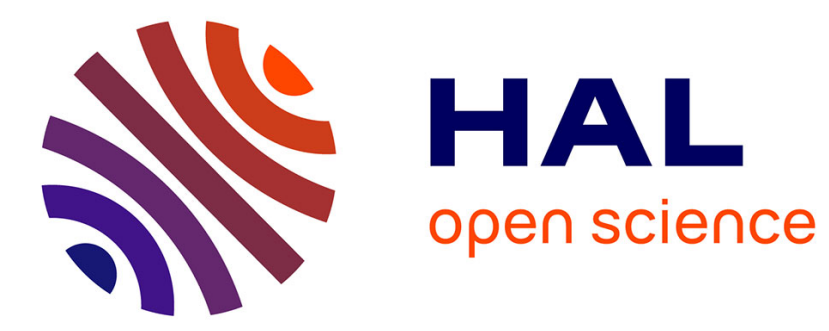

\title{
Chitosan Hydrogels Incorporating Colloids For Sustained Drug Delivery
}

Soline Peers, Alexandra Montembault, Catherine Ladaviere

\section{To cite this version:}

Soline Peers, Alexandra Montembault, Catherine Ladaviere. Chitosan Hydrogels Incorporating Colloids For Sustained Drug Delivery. Carbohydrate Polymers, 2022, 275, pp.118689. 10.1016/j.carbpol.2021.118689 . hal-03362316

\section{HAL Id: hal-03362316 https://hal.science/hal-03362316}

Submitted on 1 Oct 2021

HAL is a multi-disciplinary open access archive for the deposit and dissemination of scientific research documents, whether they are published or not. The documents may come from teaching and research institutions in France or abroad, or from public or private research centers.
L'archive ouverte pluridisciplinaire HAL, est destinée au dépôt et à la diffusion de documents scientifiques de niveau recherche, publiés ou non, émanant des établissements d'enseignement et de recherche français ou étrangers, des laboratoires publics ou privés. 


\title{
Chitosan Hydrogels Incorporating Colloids For Sustained Drug Delivery
}

\author{
S. Peers, A. Montembault*, C. Ladavière*
}

University of Lyon, CNRS, Claude Bernard Lyon 1 University, INSA, Ingénierie des Matériaux Polymères, IMP UMR 5223, 15 bd A. Latarjet, F-69622, Villeurbanne, France

* Corresponding authors: alexandra.clayer-montembault@univ-lyon1.fr (A. Montembault), catherine.ladaviere@univ-lyon1.fr (C. Ladavière)

\begin{abstract}
In today's biomedical research, a huge effort is being made towards the development of efficient drug delivery systems, achieving sustainable and controlled delivery of drugs. Chitosan (CS) hydrogels are high water content materials with very relevant biological properties to that purpose. Their use for a local and delayed delivery has already been demonstrated for a wide variety of therapeutic agents. One relatively recent strategy to improve these CS-based systems consists in the insertion of colloids, embedding drugs, within their three-dimensional matrix. This provides a second barrier to the diffusion of drugs through the system, and allows to better control their release. The main objective of this review is to report the many existing complex systems composed of CS hydrogels embedding different types of colloids used as drug delivery devices to delay the release of drugs. The various biomedical applications of such final systems are also detailed in this review.
\end{abstract}

\section{Keywords}

Chitosan; hydrogels; colloids; drug delivery systems

\section{Introduction}


Chitosan (CS) physical and chemical hydrogels are known to be very efficient and useful systems, not only to delay the release of hydrophilic, hydrophobic molecular or even macromolecular drugs (Bhattarai et al., 2010; Deen \& Loh, 2018; Elgadir et al., 2015; Giri et al., 2012; Peers et al., 2020; Ribeiro et al., 2017; Shariatinia \& Jalali, 2018), but also to better target the treatment site, with in situ injections for example (Ta et al., 2008). They can also be used for specific biomedical applications as wound healing (Hamedi et al., 2018; H. Liu et al., 2018; L. Liu et al., 2016), gastrointestinal (Hejazi \& Amiji, 2003), ophthalmic (Wang \& Han, 2017) treatments or to control angiogenesis (Ishihara et al., 2006). In the literature, three different mechanisms are described to explain the release of drugs from CS hydrogels: i) diffusion-controlled, ii) swelling-controlled, and iii) chemically-controlled release (Azevedo, 2015). However, even if CS hydrogels act as diffusion barriers for the entrapped drugs, several teams have already demonstrated that such systems undergo a non-negligible burst-effect. This phenomenon corresponds to the fast and uncontrolled delivery of a high amount of the entrapped drugs immediately upon administration (X. Huang \& Brazel, 2001).

Even if in some cases the burst release might be desirable (e.g., for encapsulated flavours or local targeted delivery), it is often considered as a detrimental consequence in most of drug delivery applications. Consequently, an intensive research is made to reduce this burst effect by designing more efficient drug delivery systems. One strategy is the incorporation of drugs into colloids that are themselves embedded into the CS hydrogel.

The main objective of this review is to report the studies described in the literature about "CS hydrogel-colloids" assemblies, specifically valorized as delivery devices of drugs. The colloids considered in this review are microparticles, nanoparticles, liposomes or even micelles (Figure 1). Their biomedical applications are also detailed herein. Note that drug nonproprietary names are employed throughout the review. Hereinafter, the word "drug" refers to active molecules of therapeutic interest, or model molecules (used for proof of concept). Furthermore, it was chosen not to detail cyclodextrin-based systems (Kono \& Teshirogi, 2015; Maestrelli et al., 2006; Zhou et al., 2016) and/or nanoemulsions (Moradi et al., 2019; dos Santos et al., 2020; Demisli et al., 2020) in this review. 


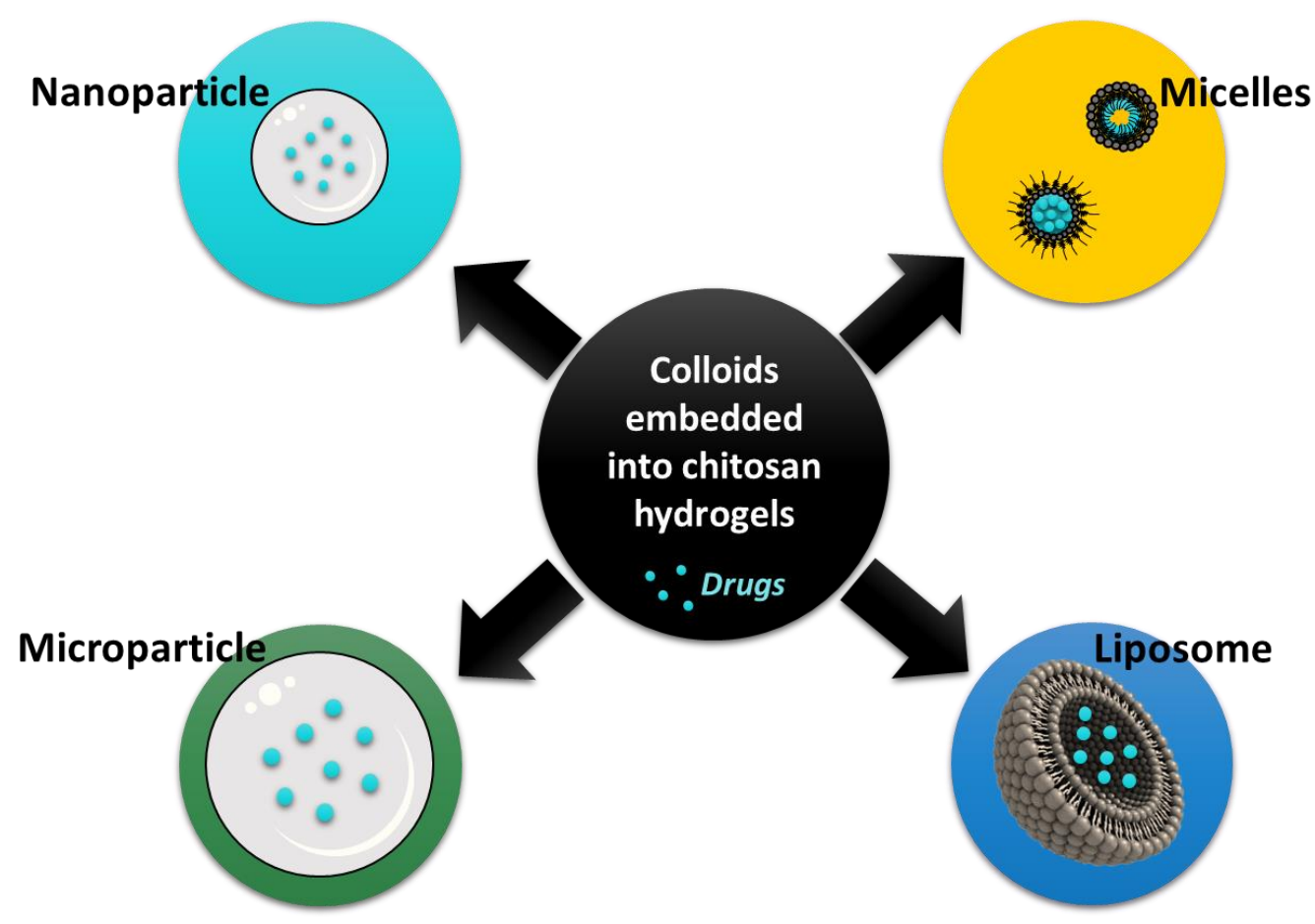

Figure 1. Schematic representation of different colloids incorporated into CS hydrogels to control and/or delay the release of drugs, described in the literature.

.

\section{4}

(6)

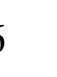
barrier to drugs' diffusion. To this end, drugs have to be firstly incorporated into the microparticles, and then into the hydrogel network formed by entangled polymer chains. In most of the cases, the insertion of polymer microparticles in CS hydrogels limits or even eliminates the burst release phenomenon, that is to say the sudden fast and uncontrolled delivery of a high amount of drugs entrapped in CS hydrogels in the first minutes/hours after administration. Burst release is observed with "traditional" hydrogels and is often related to adsorbed drugs on the hydrogel surface, that are released faster than drug molecules entrapped within the hydrogel matrix (Pitorre et al., 2017). Several experimental methods can be used for the elaboration of polymer microparticles (Li et al., 2017). In the literature, one can find phase separation (e.g., (Zan et al., 2006)), spray-drying (e.g., (Legrand et al., 2007) (Yang et al., 2017)) or a two-phases nano-emulsion elaboration (mostly « oil-in-water », but also « waterin-oil », e.g., (Moebus et al., 2009) (Qi et al., 2016) (Dehghan-Baniani et al., 2017)). More than two phases can also be prepared to create a multi-emulsion (e.g., (Legrand et al., 2007; Zhu et al., 2018)). Depending on the method employed for the microparticle elaboration, different sizes, drug incorporation rates, and morphologies of microparticles can be obtained. For 
example, it has been demonstrated that the incorporation of an antibiotic, the vancomycin (VCM) into (hydroxypropyl)methyl cellulose (HPMC) microparticles lead to more spherical morphologies than microparticles without VCM (Mahmoudian \& Ganji, 2017). In most cases, microparticles are embedded into hydrogel before its gelation process by mixing the microparticle suspension and the CS solution. This method is actually mostly used with thermosensitive hydrogels for which the microparticle suspensions are pre-formed with control of the microparticle size and dispersion, and then mixed with CS solution. Some studies thus have revealed that the incorporation of microparticles into thermosensitive hydrogels decreased the gelation time (Dehghan-Baniani et al., 2017; Mahmoudian \& Ganji, 2017; Qi et al., 2016; Yang et al., 2017; Zan et al., 2006). In these types of systems, microparticles act as crosslinking nodes and facilitate the gelation process. Such « CS hydrogel/microparticles » assemblies were valorized in different biomedical applications with various administration routes (oral, ocular or direct injection on the injury site).

A faster ulcer healing on mice dorsal skin after the application of a CS scaffold in which gelatin microparticles $(<100 \mu \mathrm{m}$, elaborated by water-in-oil emulsion) were embedded has also been shown (Park et al., 2009). A growth factor (b-FGF) was firstly incorporated into gelatin microparticles, and the final assembly was observed by confocal microscopy (Figure 2). The autofluorescent properties of gelatin and chitosan were used to capture the confocal images. No burst release phenomenon was observed with this assembly, allowing a sustained release of the b-FGF growth factor in vivo for 10 days.

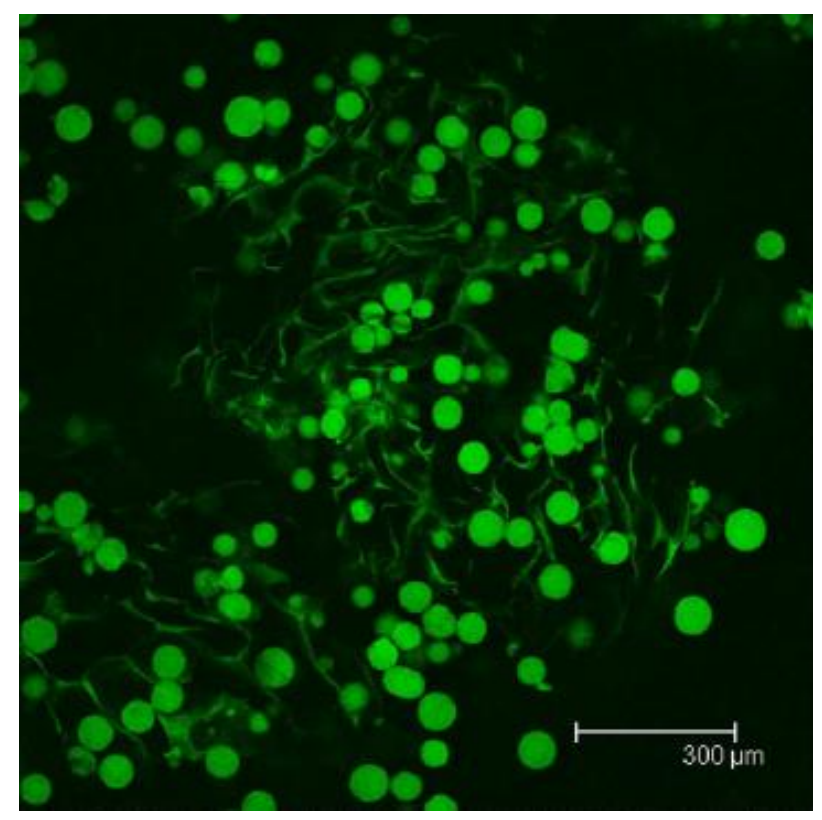

Figure 2. Confocal micrograph of gelatin microparticles in chitosan scaffold (Park et al., 2009) 
Such «CS hydrogel/microparticles » assemblies can thus support tissue regeneration. They can also be used for the sustained and delayed release of drugs incorporated into microparticles. A transforming growth factor (TGF), or a model protein (bovine serum albumin, BSA), were embedded into CS microspheres $(0,2-15 \mu \mathrm{m})$, then were incorporated into a CS scaffold for the chondrocyte proliferation enhancement and the cartilage regeneration (Kim et al., 2003).

110 Protein release profiles from these CS microspheres (diffusion process) have been presented, 111 but no information was given about the protein release from the final assemblies. This work has interestingly shown a sustained release of TGF with its incorporation into CS microspheres, inducing a high chondrocyte proliferation within the scaffold. This trend has been attributed to the ability of TGF to promote protein synthesis and chondrocyte cellular proliferation.

For articular inflammation treatment, other microparticles composed of poly(lactic-coglycolic acid) (PLGA, microparticles with diameters from 5 to $120 \mu \mathrm{m}$ ) have also been incorporated into CS hydrogels (Joung et al., 2007; Zhu et al., 2018). The release of an antiinflammatory drug, lornoxicam, from PLGA microspheres, embedded (before the CS gelation process) into an in situ gelling CS formulation leading to a chemical hydrogel was studied (Zhu et al., 2018). Only $20 \%$ of the initial incorporated drugs have been released in one hour (versus $30 \%$ when the drugs were incorporated into microspheres) with a sustained release of drugs during more than 13 days. In this study, no comparison has been done with the release of lornoxicam directly incorporated into CS hydrogels.

In vivo drug activity was also studied in mouse after intra-articular injections of particles entrapped in a CS/glycerophosphate (GP) solution (Zhu et al., 2018). Gelation of this CS/GP solution was achieved within 5 minutes after the injection, and that the CS/GP hydrogel formed was maintained at the injection site. With such a « CS/GP hydrogel/microparticles » assembly,

128 the lornoxicam concentration into the blood was lower than in the case of a direct injection of 129 a lornoxicam solution in the delivery site, which was a proof of a sustained delivery of this 130 drug.

131 Alginate microparticles, with diameters from 1 to $25 \mu \mathrm{m}$, loaded with diclofenac have also 132 been elaborated before the CS gelation process (Qi et al., 2016). These microparticles were 133 embedded into thermosensitive CS/GP physical hydrogels for the treatment of articular 134 inflammations (arthrosis). In this study, the drug was progressively released for 5 days in vitro. 135 A slowdown in the inflammation propagation was observed in vivo, but the cartilage healing 
was only partial, even after 3 weeks of treatment. However, this treatment is efficient for reducing intra-articular injections, with a minimal immune response.

Porous PLGA microparticles, with diameters ranging from 20 to $120 \mu \mathrm{m}$ and incorporating vascular endothelial growth factor (VEGF), were embedded (before the CS gelation process) into CS/alginate chemical hydrogels associated to an antibiotic, VCM, linked to the CS hydrogel via Schiff's base reaction (J. Huang et al., 2018). This assembly was efficient for the delayed release of VCM, and more particularly for wound healing applications. As a first step, the pores of PLGA microparticles were temporarily "closed" by CS/alginate solution, which drastically slows the release of the VEGF. The release of VCM was here governed by the environmental $\mathrm{pH}$. The VCM and VEGF release profiles could allow not only the treatment of infections via the fast release of an antibiotic, but also the healing of wounds by means of the sustained delivery of VEGF, enhancing vascularization and tissue regeneration.

The incorporation of PLGA microparticles (before hydrogel gelation) into CS/polyvinylpyrrolidone hydrogels to control the delivery of an anti-inflammatory drug, dexamethasone has also been studied (Saeedi Garakani et al., 2020). The use of a "hybrid" assembly considerably delays the release of the entrapped drug with $80 \%$ of the drug released after 30 days, while in the microparticles, the release was completely achieved after 22 days. When the drug was incorporated alone within the hydrogel, it was fully released in few hours, demonstrating the efficiency and interest of this system for wound healing applications. Different parameters of great interest have been studied such as mechanical properties, porosity, swelling ratio, biodegradability or antibacterial activity. For example, they observed an increase in the mechanical properties of the assembly after microparticles addition, attributed to a stiffer structure of the embedded particles compared to the hydrogel. Another interesting point is that an increase in PLGA microparticles content improved not only the mechanical properties, but also the cell viability and antibacterial activity of the systems.

Starch microparticles $(1.7-2.5 \mu \mathrm{m})$ have also been incorporated into thermosensitive CS/monoammonium phosphate physical hydrogel, with the aim of creating a mime of cartilage (Dehghan-Baniani et al., 2017). Starch was selected for its biocompatibility, biodegradability, non-toxicity and low price. These microparticles acted as new crosslinking points (Figure 3) by creating interactions between starch and CS chains that enhanced mechanical properties of the assembly (compressive elastic modulus around $28 \mathrm{kPa}$, versus $2 \mathrm{kPa}$ for pure chitosan). Such an assembly could thus be used for the delayed release of drugs, although no study has been done by this team of co-workers. 
170

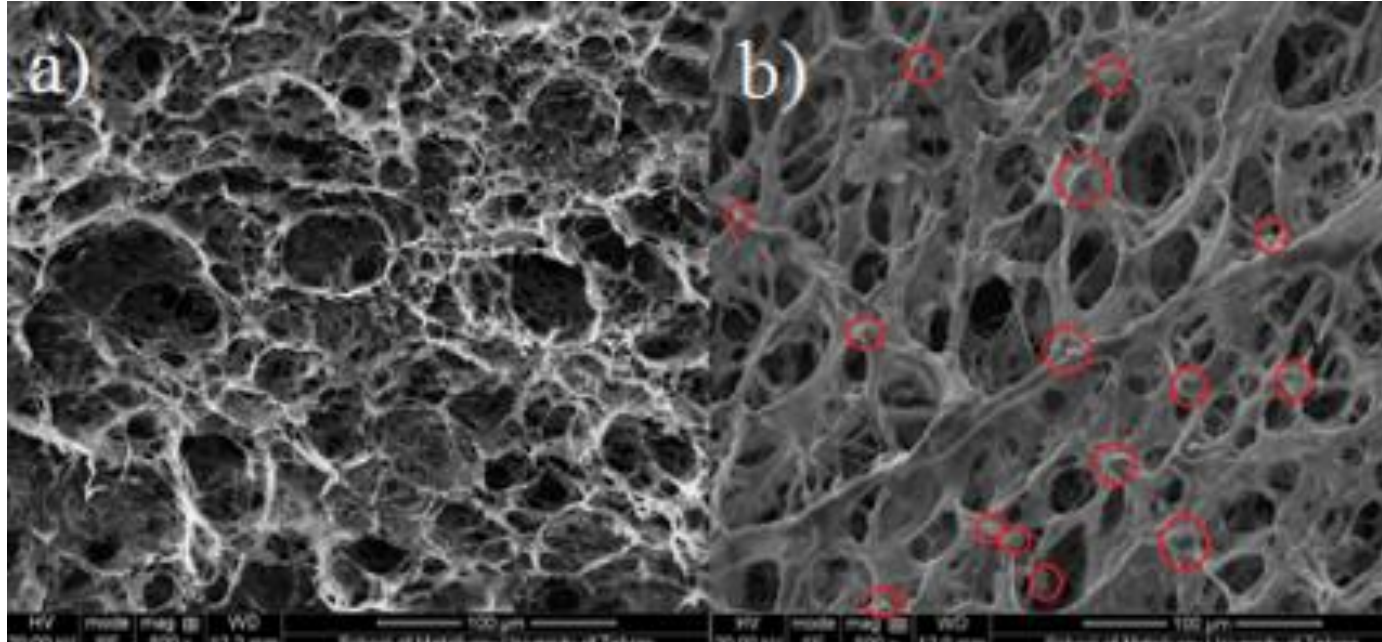

Figure 3. SEM images of a) a CS hydrogel with a porous structure, and b) a CS hydrogel incorporating starch microparticles $(0,02 \mathrm{~g} / 10 \mathrm{~mL}$ CS solution, red circles were added by the authors to display them), magnification x500 (Dehghan-Baniani et al., 2017)

Similarly, VCM was also incorporated into HPMC microparticles (about $5 \mu \mathrm{m}$ ) for the treatment of osteomyelitis (Mahmoudian \& Ganji, 2017). Its release was examined over $12 \mathrm{~h}$. When VCM was incorporated into a CS chemical hydrogel, the VCM release was delayed over more than 3 days in comparison with free VCM and VCM-loaded microparticles. Finally, 100\% of incorporated VCM was released (thanks to the double diffusion barrier) over $160 \mathrm{~h}$ when it was firstly incorporated into HPMC microparticles, themselves embedded into CS chemical hydrogel. Note that the presence of HPMC microparticles inside the CS hydrogel matrix seemed to decrease the gelation time ( $8 \mathrm{~min}$ for the « $\mathrm{CS}$ hydrogel/microparticles » assembly versus 13 min for the CS hydrogel without HPMC microparticles).

« CS hydrogel/microparticles » assemblies could also be used for the controlled delivery of anticancer drugs. Indeed, the incorporation of 5-FU into poly-3-hydroxybutyrate (PHB) microparticles with diameters from 20 to $35 \mu \mathrm{m}$, embedded into a thermosensitive CS hydrogel, has also been studied (Zan et al., 2006). The embedment of PHB microparticles into a CS/GP hydrogel decreased the rapid initial release from $85 \%$ to $29 \%$ for the optimized PHB content in the first $48 \mathrm{~h}$. Consequently, the 5-FU release was very interestingly sustained over 10 months from this «CS hydrogel/PHB microparticles » assembly.

The same drug 5-FU has been also embedded into gelatin microsphere, then incorporated (before gelation process) in chitosan-alginate hydrogels (Chen et al., 2019). The novelty of this works resides in the incorporation of magnetic nanoparticles inside the microspheres, allowing 
194 a tunable release of the entrapped drug under magnetic field. In the early hours, no significant 195 difference was observed between assembly with or without the magnetic field application. After 196 five days, cumulative release rate of 5-Fu showed a significant increase under the external magnetic field, and the final release reached $75 \%$ under magnetic fields, against only $55 \%$ for

198 the assembly without magnetic field application. A shorter gelation time has been observed, 199 lower swelling ratio and slower degradation process in vitro for "hybrid" assemblies compared 200 to the controls.

201 Microparticle insertion into a CS hydrogel could also enhance the bioadhesive properties of CS hydrogel (Yang et al., 2017). They elaborated a thermosensitive CS/GP physical hydrogel incorporating microparticles with diameters between 1.5 and $4.3 \mu \mathrm{m}$ (made of CS and a polysaccharide extracted from Bletilla Striata plant) loading Tenofivir (TFV). This drug partially prevents HIV transmission to women. These TFV-loaded microparticles were incorporated before the CS gelation process. According to their results, the mucoadhesion on vaginal mucosa followed this order: TFV incorporated in microparticles themselves inserted in the CS hydrogel > TFV incorporated in the CS hydrogel »> TFV in the microspheres > only TFV in solution. Nevertheless, note that no information about mucosa/CS hydrogel or mucosa/microparticle interactions was provided. Interestingly, they demonstrated that the burst release phenomenon was strongly limited with this « CS hydrogel/microparticles » assembly: only $13 \%, 21 \%$, and $32 \%$ of TFV released over 15,30 et 60 min respectively from this assembly, when more than $30 \%$ were released over only $30 \mathrm{~min}$ from TFV-loaded microparticles (without their incorporation in the CS hydrogel).

To conclude this part and in a more exhaustive way, the goal of Table 1 is to report works about the controlled delivery of drugs from these «CS hydrogel/microparticles » assemblies that can be found in the literature, to the best of our knowledge. 
226 Table 1. Nature and diameters of microparticles, nature of drugs inserted in microparticles of 227 «CS hydrogel/microparticles » assemblies for the controlled delivery of drugs agents used in 228 different biomedical applications

\begin{tabular}{|c|c|c|c|c|}
\hline $\begin{array}{c}\text { Microparticle } \\
\text { nature }\end{array}$ & $\begin{array}{c}\text { Microparticle } \\
\text { diameter } \\
\text { range }(\mu \mathrm{m})\end{array}$ & Drugs & $\begin{array}{l}\text { Biomedical } \\
\text { application }\end{array}$ & Reference \\
\hline \multirow{5}{*}{ Chitosan } & \multirow{4}{*}{$0,2-1,5$} & $\mathrm{TGF}^{1}$ & \multirow{5}{*}{$\begin{array}{c}\text { Tissue } \\
\text { engineering }\end{array}$} & \\
\hline & & (growth factor) & & (Kim et al., \\
\hline & & & & 2003) \\
\hline & & (model protein) & & \\
\hline & $29-40$ & BSA & & $\begin{array}{c}\text { (Fan et al., } \\
\text { 2017) }\end{array}$ \\
\hline \multirow[t]{2}{*}{ Alginate } & $1-25$ & $\begin{array}{c}\text { Diclofenac } \\
\text { (anti-inflammatory } \\
\text { drug) }\end{array}$ & $\begin{array}{l}\text { Articular } \\
\text { treatment }\end{array}$ & $\begin{array}{l}\text { (Qi et al., } \\
\text { 2016) }\end{array}$ \\
\hline & $2-10$ & BSA & $\begin{array}{c}\text { Tissue } \\
\text { engineering }\end{array}$ & $\begin{array}{c}\text { (Xing et al., } \\
\text { 2019) }\end{array}$ \\
\hline \multirow[t]{2}{*}{ Starch } & $1,7-4,5$ & Unspecified & $\begin{array}{c}\text { Tissue } \\
\text { engineering }\end{array}$ & $\begin{array}{c}\text { (Dehghan- } \\
\text { Baniani et al., } \\
\text { 2017) }\end{array}$ \\
\hline & $5-75$ & $\begin{array}{c}\text { Indometacin } \\
\text { (anti-inflammatory } \\
\text { drug) }\end{array}$ & Unspecified & $\begin{array}{c}\text { (Joung et al., } \\
\text { 2007) }\end{array}$ \\
\hline \multirow[t]{2}{*}{$\begin{array}{l}\text { Poly(lactic-co- } \\
\text { glycolic acid) }\end{array}$} & $6-7$ & $\begin{array}{c}\text { Lornoxicam } \\
\text { (anti-inflammatory } \\
\text { drug) }\end{array}$ & $\begin{array}{l}\text { Articular } \\
\text { treatment }\end{array}$ & $\begin{array}{c}\text { (Zhu et al., } \\
\text { 2018) }\end{array}$ \\
\hline & $20-120$ & $\begin{array}{c}\text { VEGF }^{3} \\
\text { (growth factor) }\end{array}$ & Wound healing & $\begin{array}{l}\text { (J. Huang et } \\
\text { al., 2018) }\end{array}$ \\
\hline
\end{tabular}


Hydroxypropyl

methylcellulose

$1,5-6,4$

poly

hydroxybutarate

20-35

40-90

CS-bletilla

striata

polysaccharide

$1,5-4,3$

Tenofovir

(antiretroviral)

b-FGF ${ }^{6}$

(growth factor)

Gelatin

0.6

5-FU
Osteomyelitis

treatment

(Mahmoudian

\& Ganji,

2017)

(Zan et al., 2006)

Adenocarcinoma

HIV transmission

prevention

(Yang et al., 2017)
Ulcer treatment

(Park et al., 2009)

Cancer treatment

and tissue

(Chen et al., regeneration 2019)

(Saeedi

PLGA

Wound healing

Garakani et

al., 2020)

${ }^{1} \mathrm{TGF}=$ transforming growth factor

${ }^{2} \mathrm{BSA}=$ bovine serum albumin

${ }^{3} \mathrm{VEGF}=$ vascular endothelial growth factor

${ }^{4} \mathrm{VCM}=$ vancomycin

${ }^{5}$ 5-FU $=5$-fluorouracil

${ }^{6} \mathrm{~b}-\mathrm{FGF}=$ basic fibroblast growth factor

2. «Chitosan hydrogel/nanoparticles » assemblies

Drugs of different nature can also be incorporated in nanoparticles. Nanoparticles could also

238 be incorporated in CS hydrogels, providing a second barrier to the diffusion of drugs, and

239 delaying their delivery (Morantes et al., 2017). As seen before for polymer microparticles,

240 different methods can be employed for the elaboration of polymer nanoparticles (Li et al.,

241 2017). For example, emulsion (mostly water-in-oil) (Peng et al., 2013; Dehghan-Baniani et al.,

242 2017), ionic gelation (Bugnicourt et al., 2014; Li Hui et al., 2016), nanoprecipitation (Legrand

243 et al., 2007) or emulsion/gelation (Qi et al., 2016) processes could be used for such a

244 preparation. 
Another biomedical application of these «CS hydrogel/nanoparticles » assemblies is the regulation of glycaemia with insulin incorporation (which commonly implies daily injections for diabetic patients). A thermosensitive CS/GP physical hydrogel for the controlled delivery of insulin, incorporating poly-3-hydroxybutarate-co-hydroxyhexanoate (PBHBHH) nanoparticles (incorporated before the CS gelation process) has also been elaborated (Peng et al., 2013). In vitro, $95 \%$ of initially incorporated insulin were released over 16 days when they were incorporated into CS/GP hydrogel. On the contrary, only less than $20 \%$ was released when the nanoparticles are firstly incorporated into CS hydrogels (Figure 4). Hypoglycaemic activity was also measured in vivo, showing an important decrease of blood glucose levels, and thus a better insulin bioavailability.

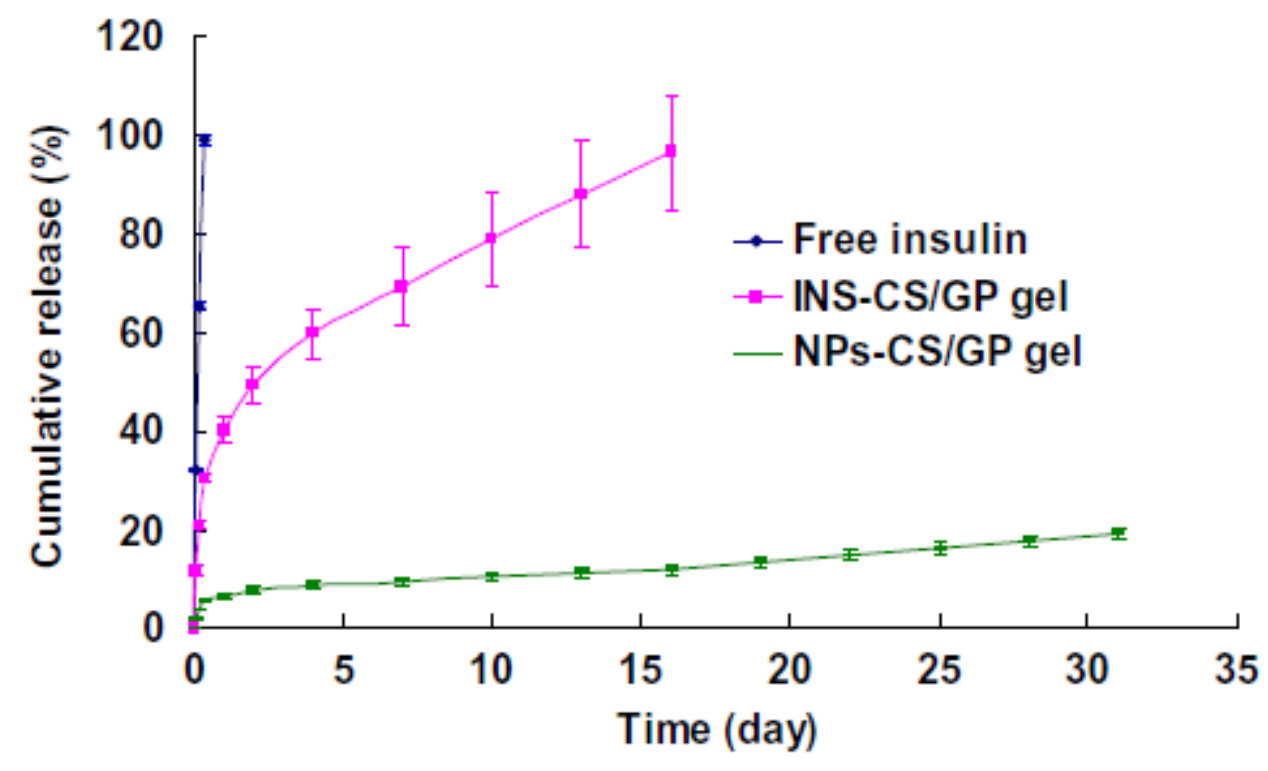

Figure 4. Cumulative release profiles (\% of initially incorporated drug) of free insulin (blue diamonds), insulin into « CS/GP hydrogels » (pink squares), or insulin in « CS/GP hydrogel/insulin loaded-PBHBHH nanoparticles » assemblies (green hyphens) (Peng et al.,

Another way to delay the release of hydrophobic drugs consists in the elaboration of a colloid suspension surrounded by one or more polymer layer(s) with a final diameter of nanocolloids around $500 \mathrm{~nm}$. This method was for example used for the controlled release of an anticancer drug, camptothecin inserted in nanocolloids, themselves covered by a trimethyl CS layer ( $\mathrm{Li}$ XingYi et al., 2010). This colloid suspension was then incorporated in a thermosensitive CS/dibasic sodium phosphate physical hydrogel (before the CS gelation process). The drug release and cytotoxicity related to the antitumor activity against specific breast cancer cells 
were studied in vitro. After proving the in vivo biodegradability of these assemblies, the in vitro

270 delayed release of camptothecin in PBS at pH 7.4 (diffusion throughout the assembly) has been

271 studied. $30 \%$ of the initially incorporated drug were released over 3 days, $70 \%$ over 18 days.

272 This assembly seemed appropriate not only for protection of drug (as nearly $90 \%$ of the

273 camptothecin were preserved in the lactone form), but also to delay its release in situ, while

274 maintaining its antitumor activity. To conclude this part and in a more exhaustive way, the goal

275 of Table 2 is to report studies about the controlled delivery of drugs from «CS

276 hydrogel/nanoparticles » assemblies that can be found in the literature, to the best of our 277 knowledge.

279 Table 2. Nature and diameters of nanoparticles, nature of drugs inserted in nanoparticles of «

280 CS hydrogel/nanoparticles » assemblies for the controlled delivery of drugs used in different 281 biomedical applications

\begin{tabular}{ccccc}
\hline $\begin{array}{c}\text { Nanoparticle } \\
\text { nature }\end{array}$ & $\begin{array}{c}\text { Nanoparticle } \\
\text { diameter range } \\
(\mathbf{n m})\end{array}$ & Drugs & $\begin{array}{c}\text { Biomedical } \\
\text { application }\end{array}$ & Ref. \\
\hline
\end{tabular}

\begin{tabular}{|c|c|c|c|c|}
\hline $\begin{array}{l}\text { Poly-3- } \\
\text { hydroxybutarate- }\end{array}$ & $\mathrm{UNS}^{1}$ & $\begin{array}{c}\text { Insulin } \\
\text { (Peptide hormone) }\end{array}$ & $\begin{array}{l}\text { Glycaemia } \\
\text { regulation }\end{array}$ & $\begin{array}{l}\text { (Peng et } \\
\text { al., 2013) }\end{array}$ \\
\hline
\end{tabular}

hydroxyhexanoate

\begin{tabular}{|c|c|c|c|c|}
\hline Chitosan & $500-900$ & $\begin{array}{c}\text { DNA-BMP } \\
\text { (DNA plasmid) }\end{array}$ & $\begin{array}{c}\text { Tissue } \\
\text { engineering }\end{array}$ & $\begin{array}{l}\text { (Li Hui et } \\
\text { al., 2016) }\end{array}$ \\
\hline Chitosan & 266 & $\begin{array}{c}\text { FGF }^{2} \\
\text { (growth factor) }\end{array}$ & $\begin{array}{c}\text { Tissue } \\
\text { engineering }\end{array}$ & $\begin{array}{c}\text { (Azizian } \\
\text { et al., } \\
\text { 2018) }\end{array}$ \\
\hline
\end{tabular}

\begin{tabular}{|c|c|c|c|c|}
\hline Trimethyl CS & 500 & $\begin{array}{l}\text { Camptothecin } \\
\text { (anticancer drug) }\end{array}$ & $\begin{array}{c}\text { Ovary cancer } \\
\text { treatment }\end{array}$ & $\begin{array}{l}\text { XingYi et } \\
\text { al., 2010) }\end{array}$ \\
\hline
\end{tabular}




\section{3. « Chitosan hydrogel/liposomes » assemblies}

286 Since the early 1990's, several research teams worked on liposomes, used as drug 287 « reservoirs », embedded in CS hydrogels. Indeed, the lipid membrane acts as a supplementary 288 barrier against the drug diffusion throughout the CS hydrogel, while limiting the toxicity of 289 incorporated drugs. This membrane also ensures a better drug stability against surrounding 290 environment. Nevertheless, a review in 2019 entitled "Liposomes-in-Chitosan Hydrogels: 291 Challenges and Opportunities for Biomedical Applications" only mentions about twenty 292 international articles on such assemblies. The combination of two systems (liposomes and CS 293 hydrogels), both of which have the ability to control the delivery of incorporated drugs, was 294 studied with different drugs depending on the targeted biomedical application (Grijalvo et al., 295 2019).

Incorporation of hydrophilic drugs in liposomes

298 Preliminary studies on «CS hydrogel/liposomes » assemblies were done for the controlled 299 delivery of a water-soluble model molecule, the bromothymol blue (BTB), incorporated into 300 the aqueous cavity of zwitterionic liposomes (phosphatidylcholine, PC). CS hydrogel was 301 chemically crosslinked with the use of ethyl-3-(3-dimethylaminopropyl) carbodiimide (EDAC) 302 (Rao \& Alamelu, 1992). It has been shown that the release of BTB was delayed, with $100 \%$ of 303 the initially incorporated BTB into liposomes released over $6 \mathrm{~h}$, versus $15-20 \mathrm{~h}$ in the case of 304 liposomes incorporated into CS hydrogels. The higher the EDAC crosslinking agent 305 concentration, the slower the release (25h for $5 \mathrm{mg}$ of added EDAC against more than $70 \mathrm{~h}$ for $30630 \mathrm{mg}$, Figure 5). 


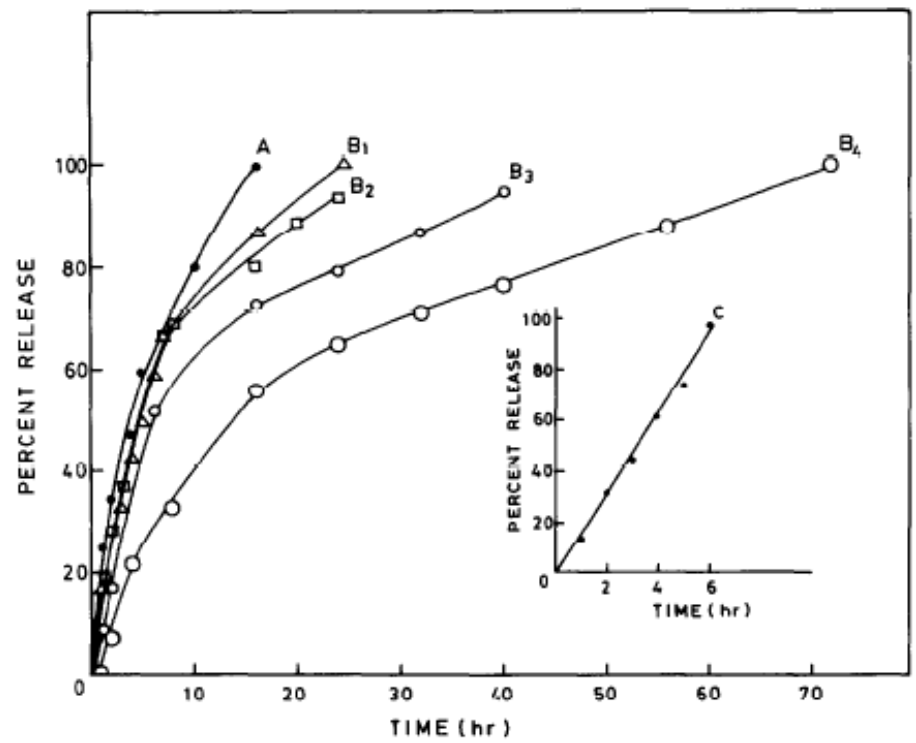

Figure 5. Influence of the EDAC crosslinking agent concentration on the cumulated release (\% of total initially incorporated drug) of BTB incorporated into PC liposomes embedded in a CS hydrogel (A) without EDAC, (B1) with $5 \mathrm{mg}$ EDAC, , (B2) $10 \mathrm{mg}$ EDAC , (B3) $20 \mathrm{mg}$ EDAC, (B4) $30 \mathrm{mg}$ EDAC. These release profiles were performed in a phosphate buffer at $\mathrm{pH}=7.4$ The $\mathrm{C}$ curve is representative of the release of BTB from free liposomes (Rao \&

Alamelu, 1992)

More recently, a sustained release of calcein over more than 20 days when this water-soluble molecule was incorporated into Phospholipon®-90G liposomes, themselves embedded in CS/gelatin chemical hydrogels. Hydrogels are crosslinked with two different crosslinking agents: glutaraldehyde and sodium sulphate or sodium triphosphate (Ciobanu et al., 2014). In this work, a significant burst effect when calcein was directly incorporated into the hydrogel has been observed. On the contrary, the incorporation of calcein into liposomes (calcein-loaded liposomes incorporated before the CS gelation process) creates a second diffusion barrier and delayed the release of calcein throughout the final assembly. Similar results have been obtained with chemical CS/gelatin hydrogels, crosslinked by glutaraldehyde or sodium tripolyphosphate, incorporating Phospholipon ${ }^{\circledR}-90 G$ liposomes (also incorporating calcein) (Paun et al., 2016). An assembly composed of CS hydrogel and Phospholipon®-90G liposomes incorporating calcein has also been elaborated (Popa et al., 2017). These hydrogels were physically crosslinked with the addition of tannic acid. The ability of this assembly to remove the burst release phenomenon, with a sustained release of calcein over few days (less than $10 \%$ of initially incorporated calcein were released after 10 days, Figure 6 right versus Figure 6 left 
displaying data obtained for CS hydrogels without liposome) has been demonstrated. This trend can be attributed to the diffusion of liposomes outside the hydrogel matrix. The liposome lipid bilayer would be then destabilized, slowly releasing the entrapped calcein.
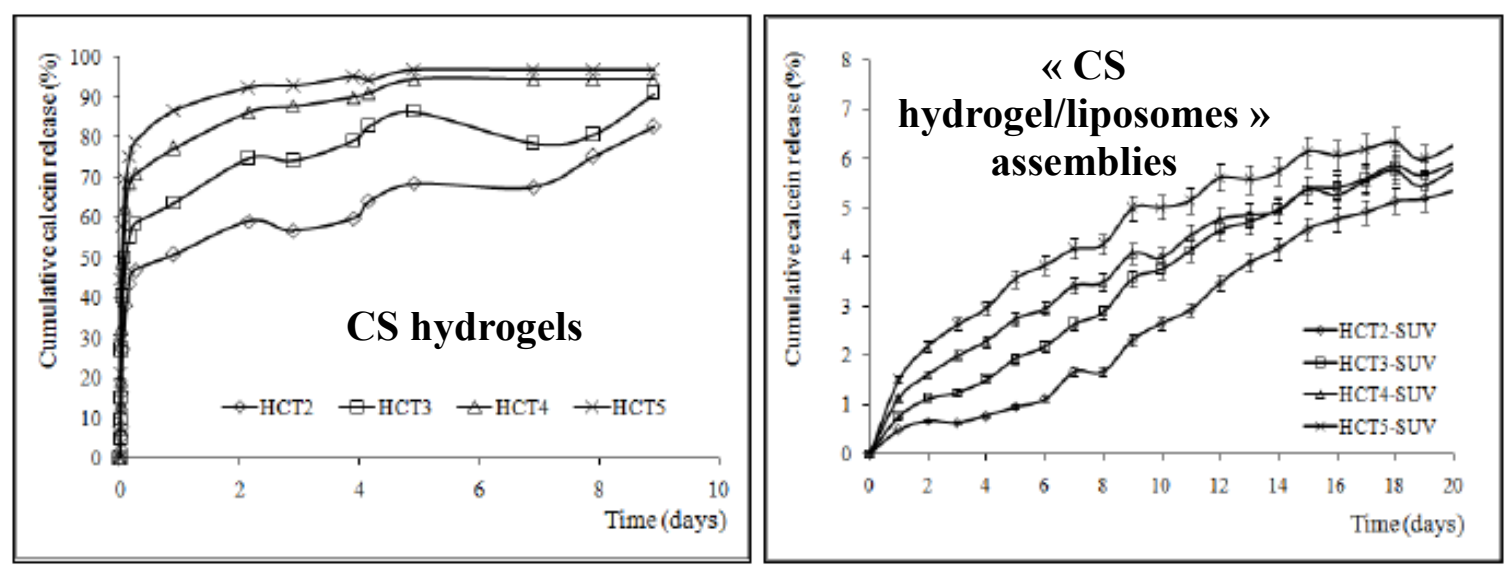

Figure 6. In vitro cumulative release of calcein under magnetic stirring (in $\mathrm{PBS}$, at $37^{\circ} \mathrm{C}, 60$ rpm) directly incorporated in CS/tannic acid hydrogels (left), or incorporated into Phospholipon ${ }^{\circledR}-90 \mathrm{G}$ liposomes embedded into CS/tannic acid hydrogels (right) with different molar ratios in CS and tannic acid (Popa et al., 2017)

Similar assemblies have been studied for wound healing after burn injuries (Hurler et al., 2012; Hurler \& Škalko-Basnet, 2012). Mupirocin, an antimicrobial agent, was incorporated into Phospholipon®-90G liposomes (mupirocin encapsulation rate between 50 and 75\%), embedded (before the CS gelation process) in CS/glycerol physical hydrogels. The double diffusion barrier of «CS hydrogel and liposomes » assemblies limits the release of mupirocin with less than a half of the initially incorporated drug released within $24 \mathrm{~h}$, whereas the total amount was released from the hydrogel without liposome over the same time. These results were confirmed by skin penetration studies, with release profiles similar to the ones obtained in vitro, which is very promising for burn injuries treatments.

Very recently, the incorporation of desferrioxamine (DFO), a chelating agent of iron and trivalent aluminium, in the aqueous cavity of dipalmitoyl-sn-glycero-3-phosphocholine (DPPC), 1, 2-distearoyl-sn-glycero-3-phosphoethanolamine-N-[amino(polyethyleneglycol)2000] (DSPE-PEG), and monostearoylphosphatidylcholine (MSPC) liposomes with a molar ratio of 85.3:9.7:5.0, respectively has been examined (O'Neill et al., 2017). Note that the DFO incorporation rate into liposomes was not mentioned in this work. These liposomes were then embedded into a thermosensitive CS/GP physical hydrogel. 
Another assembly composed of doxorubicin incorporated into PC liposomes (with a diameter around $95 \mathrm{~nm}$ ) embedded (before the CS gelation process) into thermosensitive CS/GP physical hydrogels has been elaborated (Ren et al., 2016). Two major advantages of these assemblies are: i) they are maintained on the damaged site (herein, the liver), and ii) the drug toxicity on surrounding tissues and organs is decreased. According to their results, such assemblies could delay the release of doxorubicin and decrease the burst release in the 4th first hours after injection. Indeed, only $12 \%$ of doxorubicin were released during this time for the «CS hydrogel/liposomes » assembly (drug incorporation rate in liposomes around 98\%) against around 25\% when free drug was directly incorporated in CS hydrogel. After that, the doxorubicin was slowly released from the two systems. This trend was attributed to: i) the release of doxorubicin from the cavity of the liposomes towards the hydrogel, followed by a diffusion process from the hydrogel, ii) the diffusion of the liposomes from hydrogel to the outside if their diameter is below to $100 \mathrm{~nm}$. A mathematical model of this second step from « CS hydrogel/liposomes » assemblies has been established, and have demonstrated that only the smaller liposomes could go through the hydrogel whereas the bigger ones stayed entrapped into de hydrogel matrix (Ruel-Gariépy et al., 2002). These bigger liposomes thus acted as drug reservoirs that delayed the release of doxorubicin through the system. In this latter study (RuelGariépy et al., 2002), a water-soluble model molecule, carboxyfluorescein (CF), was incorporated into PC, PC/cholesterol, or distearoylphosphatidylcholine (DSPC)/cholesterol

377 liposomes (with a CF encapsulation rate in liposomes < 8\%). These liposomes were then 378 embedded into CS/GP physical hydrogels. This study has shown that the CF diffusion was 379 strongly influenced by size and composition of liposomes embedded into hydrogels (Figure 7). 380 Furthermore, Triton-X100 was introduced to induce breakage of the lipid membrane, proving 381 the liposomes integrity before this addition. Furthermore, the bigger the liposomes, the slower 382 the release (with a CF release during several weeks for assemblies with liposomes with a 383 diameter of $280 \mathrm{~nm}$, Figure 7). 


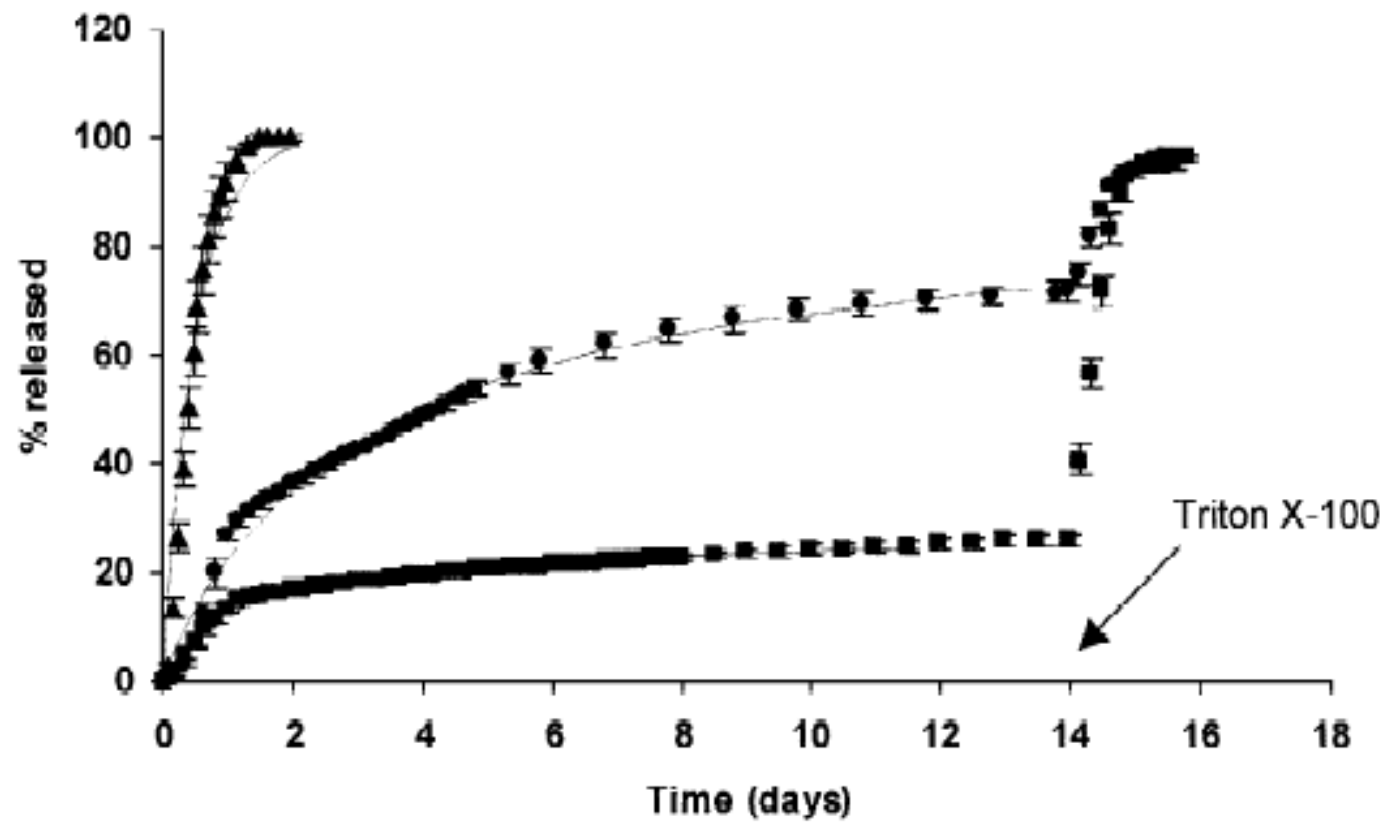

385

Figure 7. In vitro cumulative release (\% of total initially incorporated drug, in $\mathrm{PBS}$ at $37^{\circ} \mathrm{C}$ ) of free CF (triangles), or CF incorporated into $100 \mathrm{~nm}$ (circles) or $280 \mathrm{~nm}$ (squares)

PC/cholesterol liposomes (Ruel-Gariépy et al., 2002)

In ophthalmic applications, a too small amount of drugs reaching the injury site (such as cornea) is often deplored, partially due to the tear production. Patients thus need repeated drug administrations for an efficient treatment. Moreover, the cornea epithelial membrane represents a barrier to the drug diffusion across the eye (Kaur \& Kanwar, 2002). To solve this issue, ofloxacin antibiotic has been incorporated into multilamellar PC liposomes (obtained by the thin film hydration method or inverse phase evaporation) embedded into thermosensitive CS/GP physical hydrogels (Hosny, 2009). Ofloxacin incorporation rates into liposomes were found to be highly variable (between 13 and 65\%) depending on the preparation method of liposomes, and their lipid composition (e.g., the lipid charge nature). For example, incorporation rates were higher for liposomes obtained by thin film evaporation than those obtained by inverse phase evaporation (with same lipids and composition). With the liposome suspension, ofloxacin diffusion across the cornea was multiplied by 5 (versus an aqueous solution of ofloxacin). This could be explained by attractive interactions between anionic cornea and PC liposomes. Moreover, a significant increase in ofloxacin diffusion was even more observed when liposomes were embedded in CS/GP hydrogels (multiplied by 7 versus the free ofloxacin solution). Finally, it was demonstrated that the mucoadhesive properties of CS makes the interactions between liposomes and transcorneal membrane easier. 
A similar study was carried out for the controlled release of an anticancer drug, the cytarabine (Mulik et al., 2009). This drug presents a low molar mass (ca 240 g. $\mathrm{mol}^{-1}$ ), a high water-solubility, and a very short half-life in human plasma. For all these reasons, it is arduous to formulate it in a stable way, as well as to control its delivery. That is why cytarabine has been incorporated in PC liposomes (named CLLS, for cytarabine-loaded liposomal suspension, with an encapsulation rate of $c a 85 \%$ ), then embedded before gelation process in thermosensitive CS/GP physical hydrogels (named CGPCLL, for chitosan-glycerophosphate containing cytarabine-loaded liposomes).

In vitro (in $\mathrm{PBS}$, at $37^{\circ} \mathrm{C}$ ) or in vivo (intramuscular injections of $5.4 \mathrm{mg}$ of cytarabine $/ \mathrm{kg}$ in albino mice) tests have revealed that the combination of CS/GP hydrogel and liposomal suspension (CGPCLL) delayed the cytarabine release. Indeed, $85 \%$ of initially incorporated cytarabine were released over $60 \mathrm{~h}$ for assemblies (Erreur! Source du renvoi introuvable. “CGPCLL”), whereas $90 \%$ of cytarabine incorporated in liposomes were released in less than $10 \mathrm{~h}$ (“CLLS").

Very recently, a successful elaboration of biocompatible "liposomes in hydrogels" assemblies without any crosslinking agent or additives, for the delayed delivery of various water-soluble molecules has been described (Peers et al., 2019). Cumulative final releases of carboxyfluorescein (fluorescent dye), rifampicin (antibiotic), and lidocaine (anaesthetic) have revealed a delayed release of $16.9 \%, 11.6 \%$, and $7.5 \%$ between "drug-in-liposomes-inhydrogel" and "drug-in-hydrogel" assemblies, respectively. Besides the data, we have shown that the embedment of liposomes in the CS three-dimensional matrix had no impact on the rheological properties of the hydrogel, regardless of the entrapped molecule. Finally, the presence of liposomes inside the CS hydrogel network was interestingly confirmed, for the first time, by environmental scanning electron microscopy.

\section{Incorporation of hydrophobic drugs in the lipid membrane of liposomes}

The controlled delivery of hydrophobic drugs from such assemblies is also mentioned in the literature. The first study dealt with the incorporation of an antimicrobial agent, the dapsone, in the lipid membrane of PC liposomes (encapsulation rate of $c a 16 \%$ ), themselves embedded (before the CS gelation process) in CS chemical hydrogels, crosslinked with the addition of EDAC (Alamelu \& Panduranga Rao, 1994). This not only led to the liposome stabilization (Weiner et al., 1985), but also to a controlled release of dapsone. In a phosphate buffer at $\mathrm{pH}$ 
7.6, the release of dapsone was found to be 3 times slower for assemblies (86\% of dapsone released over $24 \mathrm{~h}$ ). The chemical crosslinking between liposomes and the hydrogel has doubled the time necessary to release the same amount of dapsone (in comparison with hydrogel without EDAC) supported by a decrease of the burst effect phenomenon.

In 2014, a «CS hydrogel/liposomes » assembly has been elaborated for the controlled delivery of an anticancer drug, the doxorubicin (López-Noriega Adolfo et al., 2014). This latter was incorporated in thermosensitive liposomes (composed of DPPC, MSPC, and DSPEPEG2000 with an encapsulation rate $>90 \%$ ). This thermosensitive property was brought by the addition of $10 \%$ molar of MSPC lysolipid in the formulation, which has changed the phase transition temperature of the liposome membrane, and formed pores inside the membrane with the increase of the temperature (Grüll \& Langereis, 2012; Negussie et al., 2010, 2011)). These thermosensitive liposomes were then embedded (before the CS gelation process) in a thermosensitive CS/GP physical hydrogel. Such assemblies have shown two major advantages: i) the hydrogel formation was operated at physiological temperature, and ii) the « on-demand » release of doxorubicin with the thermosensitive liposomes was possible. It has been also demonstrated that the temperature increase $\left(42^{\circ} \mathrm{C}\right)$ created pores in the lipid membrane (supported by a high release of incorporated doxorubicin). As a conclusion, these assemblies have revealed a better in vitro antitumor activity than free doxorubicin. Note that when no temperature increase was applied, only $15 \%$ of doxorubicin were released over 7 days.

Very recently, the controlled delivery of curcumin (molecule with antioxidant, antiinflammatory, and anti-bacterial properties) from liposomes with various surface charges (with an encapsulation rate between $43 \%$ and $76 \%$, depending on the liposome formulation), themselves embedded in a CS hydrogel for wound dressing applications has been investigated (Ternullo et al., 2020). Neutral liposomes were made of PC and polysorbate (weight ratio 85:15). Stearylamine (weight ratio to PC 1:9) was added for cationic liposome elaboration. Anionic liposomes were elaborated from PC and sodium deoxycholate. A sustained penetration of curcumin from resulting assemblies through the ex-vivo full human skin, which is really promising for advanced dermal delivery and wound healing applications has been evidenced.

\section{Incorporation of macromolecular drugs in liposomes}

«CS hydrogel/liposomes» assemblies were also used for the controlled delivery of macromolecular drugs, such as peptides or proteins. Aiming at a wound healing application after burn injuries, the incorporation of an epidermal growth hormone (EGF, ca $134000{\mathrm{~g} . \mathrm{mol}^{-}}^{-}$ 
$473^{1}$ ) into DPPC liposomes, themselves embedded (before the gelation process) in CS physical 474 hydrogels has also been studied (Değim et al., 2011). EGF promotes cell proliferation, as well 475 as an extracellular matrix formation during the healing process. Hormone incorporation in 476 liposomes (with an encapsulation rate close to 60\%) increased the stability of the hormone 477 (Alemdaroğlu et al., 2008; Yerushalmi et al., 1994). Daily administrations during 14 days of 478 different formulations (free EGF, liposomal EGF, and «CS hydrogel/-EGF-loaded liposomes » 479 assemblies) on rats' second-degree burn had been done to study the EGF release. According to 480 measurements of fibroblast diameters and epidermis thickness, the healing was faster for these two formulations. This could thus stabilize the incorporated macromolecular drugs, and control their release, promoting wound healing after burn injuries.

Glutathione $(\mathrm{GSH})$ has also been incorporated in extruded DSPC and dioleyphotphatidylethanolamine (DOPE) liposomes (with a not mentioned incorporation rate of GSH in liposomes) (Alinaghi et al., 2013). Liposomal GSH was then embedded in a thermosensitive CS/GP physical hydrogel, which increased the retention time of GSH into the peritoneal cavity in mouse.

In 2012, the incorporation of ovalbumin ( $\mathrm{ca} 45,000 \mathrm{~g} \cdot \mathrm{mol}^{-1}$ ), a model protein acting as an antigen, into PC and stearylamine liposomes with an encapsulation rate of around $23 \%$ has been studied (Gordon et al., 2012). These liposomes were then embedded in a thermosensitive CS/GP physical hydrogel. This work has shown a wider immune response for these assemblies, revealing their potential use as vaccines. However, this study did not result in an overall improvement in immunogenicity.

To conclude this part about liposomes incorporated into CS hydrogels, the latter embedded in CS hydrogels seem to be very efficient for the controlled release of different drugs incorporated into liposomes. The lipid membrane and the hydrogel create a double barrier to drug diffusion across the assembly. Note that no study in the literature deals with the incorporation of drugs into liposomes, themselves embedded in "pure" CS physical hydrogels, that is to say, with no additive of crosslinking agent in the final composition of the hydrogel.

As well as microparticles, nanoparticles and liposomes, micelles composed of molecular surfactants or amphiphilic polymers can also be incorporated into CS hydrogels to delay the 
release of drugs incorporated in them. Hydrophobic drugs can thus be entrapped in the inner core of direct micelles, and hydrophilic drugs, in reversed micelles. Both types of micelles act as a secondary barrier to the drug diffusion across the assembly, improving drug bioavailability. This implies the use of non-toxic additives, but also reduces the dose and associated side effects (Lundberg et al., 2003). The following part deals with such assemblies for the sustained delivery of drugs.

512 Glycol-CS chemical hydrogels associated to poly(ethylene glycol)-b-poly(propylene glycol)-b-poly(ethylene glycol) (PEO-PPO-PEO) for the controlled delivery of two anticancer drugs (doxorubicin and paclitaxel) has been elaborated (Zhao et al., 2011). Benzoic-imine bonds were thus created with a $\mathrm{pH}$ increase. Hydrophilic doxorubicin was dissolved in the CS solution, whereas hydrophobic paclitaxel was incorporated in the inner core of the (PEO-PPOPEO) micelles (Figure 8). This micellar colloidal suspension was added before the CS gelation process.

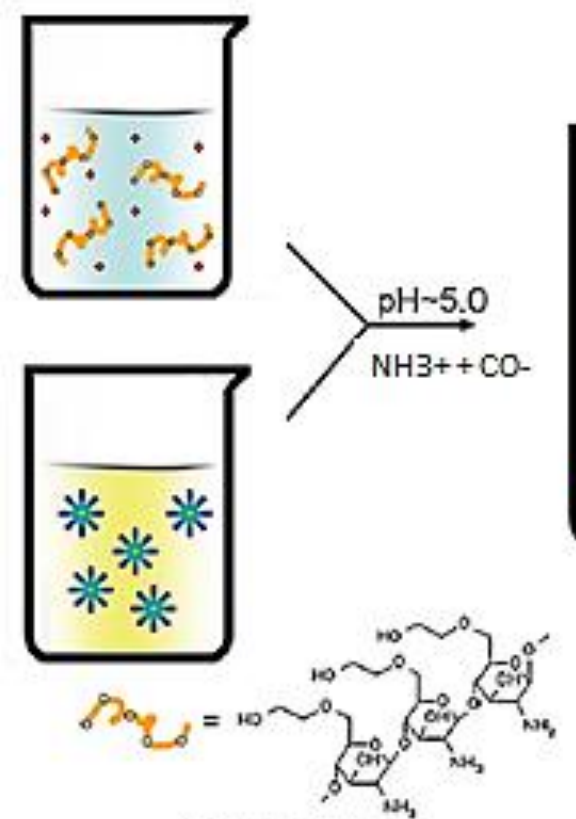

Glycol chitosan

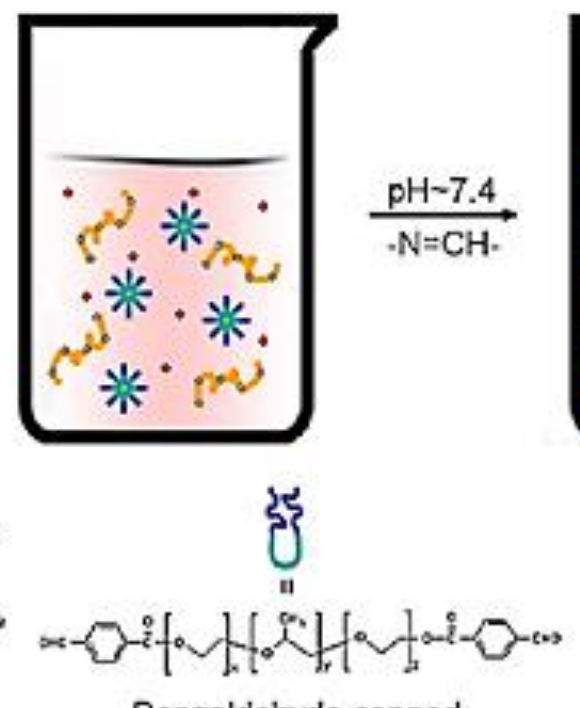

Benzaldehyde capped PEO-PPO-PEO

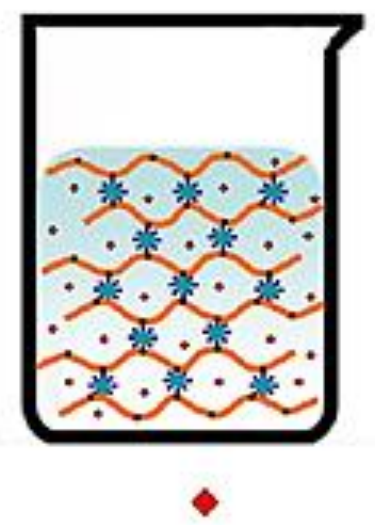

Doxorubicin

Paclitaxel

Figure 8. Schematic representation of the preparation of « doxorubicin-loaded CS chemical hydrogel/paclitaxel-loaded-PEO-PPO-PEO micelles » by Zhao et al. (Zhao et al., 2011)

It has been shown that this «doxorubicin-loaded CS chemical hydrogel/paclitaxel-loadedPEO-PPO-PEO micelles » assembly can delay the in vitro release of these two drugs over 2 weeks. The release of doxorubicin seemed to be more influenced than paclitaxel by its incorporation rate and the crosslinker content. A value of $\mathrm{pH}$ close to 6.8 increases the release 
of both drugs. This was attributed to the benzoic-imine bond within the hydrogel that is labile at this $\mathrm{pH}$ (but stable at a physiological $\mathrm{pH}$ ). This is very interesting for anticancer applications because of slightly acid tumour environment. In vivo, anti-tumour activity of both drugs was sustained which limited the tumour growth. Consequently, the survival of treated animals was enhanced (23 days for mice treated with assemblies, versus 10 days for free paclitaxel, 14 days for free doxorubicin, and 12 days for untreated mice). Such a « doxorubicin-loaded CS chemical hydrogel/paclitaxel-loaded-PEO-PPO-PEO micelles » assembly can thus be valorized for the simultaneous delivery of drugs with different natures.

Similarly, the simultaneous delivery of two different drugs from «CS hydrogel/micelles » assemblies has been studied (Wei et al., 2009). The doxorubicin was incorporated into micelles composed of a triblock copolymer of (poly(glutamic acid)-b-poly (propylene oxide)-bpoly(glutamic acid), ca 11,000 g. $\mathrm{mol}^{-1}$ ), themselves embedded (before the CS gelation process) into a thermosensitive CS/poly(vinyl alcohol) (PVA) chemical hydrogel containing acetylsalicylic acid. More than $75 \%$ of the initially incorporated acetylsalicylic acid was released over $12 \mathrm{~h}$ contrary to the same amount of doxorubicin that was released from micelles over more than a week. A pH-sensitive release of acetylsalicylic acid has been shown: the higher the $\mathrm{pH}$, the faster the release. This behaviour was can be explained by the hydrogel retraction and a water expulsion, which fostered the acetylsalicylic acid release (in vitro measurements carried out at $\mathrm{pH}=4.0 ; 5.5 ; 7.4$, and 8.4). Finally, an increase in local temperature (from 20 to $37^{\circ} \mathrm{C}$ ) leads to a faster release of drugs. This study interestingly proved that the drug release can be influenced by various stimuli such as $\mathrm{pH}$ or temperature, and that the drug release could be delayed after drug incorporation into polymer micelles.

Micelles can also incorporate hydrophobic antibiotics. A hydrophobic antibiotic, the tetracycline, has been incorporated into polymer micelles composed of PEG and PLA (di-block, ca 7,000 g. $\mathrm{mol}^{-1}$ ) (Ito et al., 2018). These PEG-PLA micelles were then embedded into PEG modified-CS chemical hydrogels (CS chains were modified by PEG chains to adjust the CS gelation properties). It has been shown that no matter the length of PEG or PLA chains in micelles (with a diameter of micelles $\simeq 20 \mathrm{~nm}$ ), a slower release was obtained (versus free drug directly incorporated into the hydrogel matrix). Micelles acted as a diffusion barrier, thus delaying the release of tetracycline. Only $30 \%$ of tetracycline were released over $20 \mathrm{~h}$ from «PEG-CS hydrogel/tetracycline-loaded PEG-PLA micelles » assemblies, versus more than $50 \%$ when the tetracycline was directly incorporated into the PEG-CS hydrogel matrix. 
To conclude this part about «CS hydrogel/micelles », as previously for micro- and nanoparticles, and liposomes, micelles seem to be efficient for delaying the release of drugs when incorporated in these assemblies. Different types of drugs can also be embedded in these systems, improving drastically the treatment efficiency.

\section{Discussion and conclusion}

This paper reviews studies described in the literature about the elaboration and the biomedical uses of complex CS-based systems, composed of drugs incorporated in « CS hydrogel/colloids » assemblies, with the aim of reducing the burst effect, and delaying the release of drugs over longer periods. Drugs are usually firstly incorporated in the colloidal objects, themselves embedded in the CS solution before the CS gelation process. Different colloids were considered such as micro- and nanoparticles, liposomes, as well as micelles. One can note that the most of studies that dealt with polymer micro and nanoparticles, whereas the number of researchers working on the incorporation of micelles into CS hydrogels is the most limited. Colloids' elaboration, drug loading, stability, and (bio)compatibility are key parameters to take in account to optimize the final systems even before their incorporation into hydrogels. All these final "hybrid" assemblies demonstrate a very interesting potential for drugs delivery applications, with the colloids acting as a second diffusion barrier of drugs regarding of the type of colloid employed. Their release through the systems is not only delayed, but their side effects are also reduced. Furthermore, the embedment of drugs with different natures (hydrophilic, hydrophobic, and macromolecular) is facilitated. In particular, the incorporation of hydrophobic or macromolecular drugs can be efficient with the use of appropriate colloids, while this incorporation could be challenging directly in CS hydrogels due to the hydrophilic behaviour of CS. Furthermore, as shown by different research teams, drugs can be released in two stages, which could be of interest for specific treatments such as wound healing for example. These "hybrid" assemblies thus open the door to a wider range of biomedical applications.

However, there is still plenty of room left for new researches and future improvements. For instance, the structural characteristics of CS used (i.e., its molar mass and acetylation degree) are not systematically given in papers. Only ca $45 \%$ of the papers cited in this review provide the molar mass (from 50,000 to 670,000 g.mol-1, the other papers only mention "low/medium/or high molar mass), and $30 \%$ of the papers, the viscosity of the resulting chitosan solution. And ca $70 \%$ of the papers mention the value of the acetylation degree: rather low 
591 acetylation degrees, from 5 to $25 \%$. Consequently, it would be interesting to determine if these 592 characteristics can be linked to release properties, and to targeted biomedical applications.

593 Furthermore, hydrogels composed of CS and another polymer (e.g., interpenetrating 594 polymer network hydrogels) could be useful to give to the final material some interesting 595 properties such as a denser hydrogel that could favour a more sustained drug delivery. Another 596 possible goal for future researches could be to work on the elaboration of such systems with 597 less (if any) chemical or physical crosslinkers in the final state, to create more health-friendly 598 systems. Indeed, chemical and physical crosslinkers could represent a real danger for such 599 biomedical applications. Finally, a better understanding of mechanisms involved after 600 administration of these "hybrid" assemblies could be relevant to even more enhance the 601 sustainable release of the entrapped drugs, and thus improve the treatment efficiency.

602

\section{Acknowledgments}

604 This work was financially supported by a grant from the French Ministry of Higher 605 Education and Research.

606 


\section{References}

608

609

610

611

612

613

614

615

616

617

618

619

620

621

622

623

624

625

626

627

628

629

630

631

632

Alamelu, S., \& Panduranga Rao, K. (1994). Liposomes sequestered in chitosan gel as a delivery device for dapsone. Carbohydrate Polymers, 24(3), 215-221. https://doi.org/10.1016/0144-8617(94)90133-3

Alemdaroğlu, C., Degim, Z., Celebi, N., Şengezer, M., Alömeroglu, M., \& Nacar, A. (2008). Investigation of epidermal growth factor containing liposome formulation effects on burn wound healing. Journal of Biomedical Materials Research Part A, 85A(1), 271283. https://doi.org/10.1002/jbm.a.31588

Alinaghi, A., Rouini, M. R., Daha, F. J., \& Moghimi, H. R. (2013). Hydrogel-embeded vesicles, as a novel approach for prolonged release and delivery of liposome, in vitro and in vivo. Journal Liposome Research, 23(3), 235-243. https://doi.org/10.3109/08982104.2013.799179

Azevedo, E. P. D. (2015). Chitosan hydrogels for drug delivery and tissue engineering applications. International Journal of Pharmacy and Pharmaceutical Sciences, 7(12), $8-14$.

Azizian, S., Hadjizadeh, A., \& Niknejad, H. (2018). Chitosan-gelatin porous scaffold incorporated with Chitosan nanoparticles for growth factor delivery in tissue engineering. Carbohydrate Polymers. https://doi.org/10.1016/j.carbpol.2018.07.023

Bhattarai, N., Gunn, J., \& Zhang, M. (2010). Chitosan-based hydrogels for controlled, localized drug delivery. Advanced Drug Delivery Reviews, 62(1), 83-99. https://doi.org/10.1016/j.addr.2009.07.019

Bugnicourt, L., Alcouffe, P., \& Ladavière, C. (2014). Elaboration of chitosan nanoparticles: Favorable impact of a mild thermal treatment to obtain finely divided, spherical, and colloidally stable objects. Colloids and Surfaces A: Physicochemical and Engineering Aspects, 457, 476-486. https://doi.org/10.1016/j.colsurfa.2014.06.029 
633 Chen, X., Fan, M., Tan, H., Ren, B., Yuan, G., Jia, Y., Li, J., Xiong, D., Xing, X., Niu, X., \&

634

635

636

637

638

639

640

641

642

643

644

645

646

647

648

649

650

651

652

653

654

655

656

657

$\mathrm{Hu}$, X. (2019). Magnetic and self-healing chitosan-alginate hydrogel encapsulated gelatin microspheres via covalent cross-linking for drug delivery. Materials Science and Engineering: C, 101, 619-629. https://doi.org/10.1016/j.msec.2019.04.012

Ciobanu, B. C., Cadinoiu, A. N., Popa, M., Desbrières, J., \& Peptu, C. A. (2014). Modulated release from liposomes entrapped in chitosan/gelatin hydrogels. Materials Science and Engineering: C, 43, 383-391. https://doi.org/10.1016/j.msec.2014.07.036

Deen, G. R., \& Loh, X. J. (2018). Stimuli-Responsive Cationic Hydrogels in Drug Delivery Applications. Gels, 4(1), 13. https://doi.org/10.3390/gels4010013

Değim, Z., Çelebi, N., Alemdaroğlu, C., Deveci, M., Öztürk, S., \& Özoğul, C. (2011). Evaluation of chitosan gel containing liposome-loaded epidermal growth factor on burn wound healing. International Wound Journal, 8(4), 343-354. https://doi.org/10.1111/j.1742-481X.2011.00795.x

Dehghan-Baniani, D., Bagheri, R., \& Solouk, A. (2017). Preparation and characterization of a composite biomaterial including starch micro/nano particles loaded chitosan gel. Carbohydrate Polymers, 174, 633-645. https://doi.org/10.1016/j.carbpol.2017.06.095

Demisli, S., Mitsou, E., Pletsa, V., Xenakis, A., \& Papadimitriou, V. (2020). Development and Study of Nanoemulsions and Nanoemulsion-Based Hydrogels for the Encapsulation of Lipophilic Compounds. $\quad$ Nanomaterials, $\quad$ 10(12), 2464. https://doi.org/10.3390/nano10122464

dos Santos, M. K., Kreutz, T., Danielli, L. J., De Marchi, J. G. B., Pippi, B., Koester, L. S., Fuentefria, A. M., \& Limberger, R. P. (2020). A chitosan hydrogel-thickened nanoemulsion containing Pelargonium graveolens essential oil for treatment of vaginal candidiasis. Journal of Drug Delivery Science and Technology, 56, 101527. https://doi.org/10.1016/j.jddst.2020.101527 
Elgadir, M. A., Uddin, Md. S., Ferdosh, S., Adam, A., Chowdhury, A. J. K., \& Sarker, Md. Z. I. (2015). Impact of chitosan composites and chitosan nanoparticle composites on various drug delivery systems: A review. Journal of Food and Drug Analysis, 23(4), 619-629. https://doi.org/10.1016/j.jfda.2014.10.008

Fan, M., Ma, Y., Tan, H., Jia, Y., Zou, S., Guo, S., Zhao, M., Huang, H., Ling, Z., Chen, Y., \& Hu, X. (2017). Covalent and injectable chitosan-chondroitin sulfate hydrogels embedded with chitosan microspheres for drug delivery and tissue engineering. Materials Science and Engineering: C, $71, \quad 67-74$. https://doi.org/10.1016/j.msec.2016.09.068

Giri, T. K., Thakur, A., Alexander, A., Ajazuddin, Badwaik, H., \& Tripathi, D. K. (2012). Modified chitosan hydrogels as drug delivery and tissue engineering systems: Present status and applications. Acta Pharmaceutica Sinica B, 2(5), 439-449. https://doi.org/10.1016/j.apsb.2012.07.004

Gordon, S., Young, K., Wilson, R., Rizwan, S., Kemp, R., Rades, T., \& Hook, S. (2012). Chitosan hydrogels containing liposomes and cubosomes as particulate sustained release vaccine delivery systems. Journal of Liposome Research, 22(3), 193-204. https://doi.org/10.3109/08982104.2011.637502

Grijalvo, S., Eritja, R., \& Díaz, D. D. (2019). Liposomes-in-Chitosan Hydrogels: Challenges and Opportunities for Biomedical Applications. In Materials Science and Technology (pp. 1-32). American Cancer Society. https://doi.org/10.1002/9783527603978.mst0484

Grüll, H., \& Langereis, S. (2012). Hyperthermia-triggered drug delivery from temperaturesensitive liposomes using MRI-guided high intensity focused ultrasound. Journal of Controlled Release, 161(2), 317-327. https://doi.org/10.1016/j.jconrel.2012.04.041 
Hamedi, H., Moradi, S., Hudson, S. M., \& Tonelli, A. E. (2018). Chitosan based hydrogels and their applications for drug delivery in wound dressings: A review. Carbohydrate Polymers, 199, 445-460. https://doi.org/10.1016/j.carbpol.2018.06.114

Hejazi, R., \& Amiji, M. (2003). Chitosan-based gastrointestinal delivery systems. Journal of Controlled Release, 89(2), 151-165. https://doi.org/10.1016/S0168-3659(03)00126-3

Hosny, K. M. (2009). Preparation and Evaluation of Thermosensitive Liposomal Hydrogel for Enhanced Transcorneal Permeation of Ofloxacin. AAPS PharmSciTech, 10(4), 13361342. https://doi.org/10.1208/s12249-009-9335-x

Huang, J., Ren, J., Chen, G., Li, Z., Liu, Y., Wang, G., \& Wu, X. (2018). Tunable sequential drug delivery system based on chitosan/hyaluronic acid hydrogels and PLGA microspheres for management of non-healing infected wounds. Materials Science and Engineering: C, 89, 213-222. https://doi.org/10.1016/j.msec.2018.04.009

Huang, X., \& Brazel, C. S. (2001). On the importance and mechanisms of burst release in matrix-controlled drug delivery systems. Journal of Controlled Release, 73(2-3), 121136. https://doi.org/10.1016/S0168-3659(01)00248-6

Hurler, J., Berg, O. A., Skar, M., Conradi, A. H., Johnsen, P. J., \& Škalko-Basnet, N. (2012). Improved Burns Therapy: Liposomes-in-Hydrogel Delivery System for Mupirocin. Journal of Pharmaceutical Sciences, 101(10), 3906-3915. https://doi.org/10.1002/jps.23260

Hurler, J., \& Škalko-Basnet, N. (2012). Potentials of Chitosan-Based Delivery Systems in Wound Therapy: Bioadhesion Study. Journal of Functional Biomaterials, 3(1), 37-48. https://doi.org/10.3390/jfb3010037

Ishihara, M., Obara, K., Nakamura, S., Fujita, M., Masuoka, K., Kanatani, Y., Takase, B., Hattori, H., Morimoto, Y., Ishihara, M., Maehara, T., \& Kikuchi, M. (2006). Chitosan 
hydrogel as a drug delivery carrier to control angiogenesis. Journal of Artificial Organs, 9(1), 8-16. https://doi.org/10.1007/s10047-005-0313-0

707

708

709

710

711

712

713

714

715

716

717

718

719

720

721

722

723

724

Ito, T., Takami, T., Uchida, Y., \& Murakami, Y. (2018). Chitosan gel sheet containing drug carriers with controllable drug-release properties. Colloids and Surfaces B: Biointerfaces, 163, 257-265. https://doi.org/10.1016/j.colsurfb.2017.12.054

Joung, Y. K., Choi, J. H., Park, K. M., \& Park, K. D. (2007). PLGA microparticle-embedded thermosensitive hydrogels for sustained release of hydrophobic drugs. Biomedical Materials, 2(4), 269. https://doi.org/10.1088/1748-6041/2/4/010

Kaur, I. P., \& Kanwar, M. (2002). Ocular Preparations: The Formulation Approach. Drug Development and Industrial Pharmacy, 28(5), 473-493. https://doi.org/10.1081/DDC120003445

Kim, S. E., Park, J. H., Cho, Y. W., Chung, H., Jeong, S. Y., Lee, E. B., \& Kwon, I. C. (2003). Porous chitosan scaffold containing microspheres loaded with transforming growth factor- $\beta 1$ : Implications for cartilage tissue engineering. Journal of Controlled Release, 91(3), 365-374. https://doi.org/10.1016/S0168-3659(03)00274-8

Kono, H., \& Teshirogi, T. (2015). Cyclodextrin-grafted chitosan hydrogels for controlled drug delivery. International Journal of Biological Macromolecules, 72, 299-308. https://doi.org/10.1016/j.ijbiomac.2014.08.030

Legrand, P., Benoit, J.-P., Briançon, S., Fattal, E., Fessi, H., \& Passirani, C. (2007). Sphéroïides et formes vectorisées. In Maloine (Ed.), Pharmacie Galénique: Formulation et Technologie pharmaceutique (pp. 221-250). Maloine. https://hal.archivesouvertes.fr/hal-00385473

Li Hui, Ji Qiuxia, Chen Ximin, Sun Yan, Xu Quanchen, Deng Panpan, Hu Fang, \& Yang Jianjun. (2016). Accelerated bony defect healing based on chitosan thermosensitive hydrogel scaffolds embedded with chitosan nanoparticles for the delivery of BMP2 
plasmid DNA. Journal of Biomedical Materials Research Part A, 105(1), 265-273. https://doi.org/10.1002/jbm.a.35900

732

733

Li, Q., Cai, T., Huang, Y., Xia, X., Cole, S. P. C., \& Cai, Y. (2017). A Review of the Structure, Preparation, and Application of NLCs, PNPs, and PLNs. Nanomaterials, 7(6), 122. https://doi.org/10.3390/nano7060122

Li XingYi, Kong XiangYe, Zhang Juan, Wang YingJing, Wang YuJun, Shi Shuai, Guo Gang, Luo Feng, Zhao Xia, Wei YuQuan, \& Qian ZhiYong. (2010). A novel composite hydrogel based on chitosan and inorganic phosphate for local drug delivery of camptothecin nanocolloids. Journal of Pharmaceutical Sciences, 100(1), 232-241. https://doi.org/10.1002/jps.22256

Liu, H., Wang, C., Li, C., Qin, Y., Wang, Z., Yang, F., Li, Z., \& Wang, J. (2018). A functional chitosan-based hydrogel as a wound dressing and drug delivery system in the treatment of wound healing. RSC Advances, 8(14), 7533-7549. https://doi.org/10.1039/C7RA13510F

Liu, L., Gao, Q., Lu, X., \& Zhou, H. (2016). In situ forming hydrogels based on chitosan for drug delivery and tissue regeneration. Asian Journal of Pharmaceutical Sciences, 11(6), 673-683. https://doi.org/10.1016/j.ajps.2016.07.001

López-Noriega Adolfo, Hastings Conn L., Ozbakir Burcin, O’Donnell Kathleen E., O’Brien Fergal J., Storm Gert, Hennink Wim E., Duffy Garry P., \& Ruiz-Hernández Eduardo. (2014). Hyperthermia-Induced Drug Delivery from Thermosensitive Liposomes Encapsulated in an Injectable Hydrogel for Local Chemotherapy. Advanced Healthcare Materials, 3(6), 854-859. https://doi.org/10.1002/adhm.201300649

Lundberg, B. B., Risovic, V., Ramaswamy, M., \& Wasan, K. M. (2003). A lipophilic paclitaxel derivative incorporated in a lipid emulsion for parenteral administration. Journal of Controlled Release, 86(1), 93-100. https://doi.org/10.1016/S0168-3659(02)00323-1 
Maestrelli, F., González-Rodríguez, M. L., Rabasco, A. M., \& Mura, P. (2006). Effect of preparation technique on the properties of liposomes encapsulating ketoprofencyclodextrin complexes aimed for transdermal delivery. International Journal of Pharmaceutics, 312(1-2), 53-60. https://doi.org/10.1016/j.ijpharm.2005.12.047

Mahmoudian, M., \& Ganji, F. (2017). Vancomycin-loaded HPMC microparticles embedded within injectable thermosensitive chitosan hydrogels. Progress in Biomaterials, 1-8. https://doi.org/10.1007/s40204-017-0066-X

Moebus, K., Siepmann, J., \& Bodmeier, R. (2009). Alginate-poloxamer microparticles for controlled drug delivery to mucosal tissue. European Journal of Pharmaceutics and Biopharmaceutics, 72(1), 42-53. https://doi.org/10.1016/j.ejpb.2008.12.004

Moradi, S., Barati, A., Salehi, E., Tonelli, A. E., \& Hamedi, H. (2019). Preparation and characterization of chitosan based hydrogels containing cyclodextrin inclusion compounds or nanoemulsions of thyme oil. Polymer International, 68(11), 1891-1902. https://doi.org/10.1002/pi.5899

Morantes, S. J., Buitrago, D. M., Ibla, J. F., García, Y. M., Lafaurie, G. I., \& Parraga, J. E. (2017). Composites of hydrogels and nanoparticles. In Biopolymer-Based Composites (pp. 107-138). Elsevier. https://doi.org/10.1016/B978-0-08-101914-6.00005-3

Mulik, R., Kulkarni, V., \& Murthy, R. S. R. (2009). Chitosan-Based Thermosensitive Hydrogel Containing Liposomes for Sustained Delivery of Cytarabine. Drug Development and Industrial Pharmacy, 35(1), 49-56. https://doi.org/10.1080/03639040802178144

Negussie, A. H., Miller, J. L., Reddy, G., Drake, S. K., Wood, B. J., \& Dreher, M. R. (2010). Synthesis and in vitro evaluation of cyclic NGR peptide targeted thermally sensitive liposome. Journal of Controlled Release, 143(2), 265-273. https://doi.org/10.1016/j.jconrel.2009.12.031 
Negussie, A. H., Yarmolenko, P. S., Partanen, A., Ranjan, A., Jacobs, G., Woods, D., Bryant, H., Thomasson, D., Dewhirst, M. W., Wood, B. J., \& Dreher, M. R. (2011). Formulation and characterisation of magnetic resonance imageable thermally sensitive liposomes for use with magnetic resonance-guided high intensity focused ultrasound. International Journal of Hyperthermia : The Official Journal of European Society for Hyperthermic Oncology, North American Hyperthermia Group, 27(2), 140-155. https://doi.org/10.3109/02656736.2010.528140

O’Neill, H. S., Herron, C. C., Hastings, C. L., Deckers, R., Lopez Noriega, A., Kelly, H. M., Hennink, W. E., McDonnell, C. O., O’Brien, F. J., Ruiz-Hernández, E., \& Duffy, G. P. (2017). A stimuli responsive liposome loaded hydrogel provides flexible on-demand release of therapeutic agents. Acta Biomaterialia, 48, 110-119. https://doi.org/10.1016/j.actbio.2016.10.001

Park, C. J., Clark, S. G., Lichtensteiger, C. A., Jamison, R. D., \& Johnson, A. J. W. (2009). Accelerated wound closure of pressure ulcers in aged mice by chitosan scaffolds with and without bFGF. Acta Biomaterialia, 5(6), 1926-1936. https://doi.org/10.1016/j.actbio.2009.03.002

Paun, V. A., Popa, M., Desbrieres, J., Peptu, C. A., Dragan, S. V., Zegan, G., \& Cioca, G. (2016). Liposome loaded chitosan hydrogels, a promising way to reduce the burst effect in drug release a comparativ analysis. Mater. Plast., 53(4), 590-593.

Peers, S., Alcouffe, P., Montembault, A., \& Ladavière, C. (2019). Embedment of Liposomes into Chitosan Physical Hydrogel for the Delayed Release of Antibiotics or Anaesthetics, and its First ESEM Characterization. Carbohydrate Polymers, 115532. https://doi.org/10.1016/j.carbpol.2019.115532 
802

803

804

805

806

807

808

809

810

811

812

813

814

815

816

817

818

819

820

821

822

823

824

825

826

Peers, S., Montembault, A., \& Ladavière, C. (2020). Chitosan hydrogels for sustained drug delivery. Journal of Controlled Release, 326, 150-163. https://doi.org/10.1016/j.jconrel.2020.06.012

Peng, Q., Sun, X., Gong, T., Wu, C.-Y., Zhang, T., Tan, J., \& Zhang, Z.-R. (2013). Injectable and biodegradable thermosensitive hydrogels loaded with PHBHHx nanoparticles for the sustained and controlled release of insulin. Acta Biomaterialia, 9(2), 5063-5069. https://doi.org/10.1016/j.actbio.2012.09.034

Pitorre, M., Gondé, H., Haury, C., Messous, M., Poilane, J., Boudaud, D., Kanber, E., Rossemond Ndombina, G. A., Benoit, J.-P., \& Bastiat, G. (2017). Recent advances in nanocarrier-loaded gels: Which drug delivery technologies against which diseases? Journal of Controlled Release, 266(Supplement C), 140-155. https://doi.org/10.1016/j.jconrel.2017.09.031

Popa, M., Ciobanu, B. C., Ochiuz, L., Desbrieres, J., \& Peptu, C. A. (2017). Controlling the release kinetics of calcein loaded liposomes from chitosan/tannic acid and chitosan/poly(vinyl alcohol)/tannic acid hydrogels. Cellulose Chemistry and Technology, 52(5-6), 353-370.

Qi, X., Qin, X., Yang, R., Qin, J., Li, W., Luan, K., Wu, Z., \& Song, L. (2016). Intra-articular Administration of Chitosan Thermosensitive In Situ Hydrogels Combined With Diclofenac Sodium-Loaded Alginate Microspheres. Journal of Pharmaceutical Sciences, 105(1), 122-130. https://doi.org/10.1016/j.xphs.2015.11.019

Rao, K. P., \& Alamelu, S. (1992). Effect of crosslinking agent on the release of an aqueous marker from liposomes sequestered in collagen and chitosan gels. Journal of Membrane Science, 71(1), 161-167. https://doi.org/10.1016/0376-7388(92)85015-B

Ren, S., Dai, Y., Li, C., Qiu, Z., Wang, X., Tian, F., Zhou, S., Liu, Q., Xing, H., Lu, Y., Chen, X., \& Li, N. (2016). Pharmacokinetics and pharmacodynamics evaluation of a 
thermosensitive chitosan based hydrogel containing liposomal doxorubicin. European Journal of Pharmaceutical Sciences, 92, 137-145. https://doi.org/10.1016/j.ejps.2016.07.002

Ribeiro, L. N. M., Alcântara, A. C. S., Rodrigues da Silva, G. H., Franz-Montan, M., Nista, S. V. G., Castro, S. R., Couto, V. M., Guilherme, V. A., \& de Paula, E. (2017). Advances in Hybrid Polymer-Based Materials for Sustained Drug Release. International Journal of Polymer Science, 2017, 1-16. https://doi.org/10.1155/2017/1231464

Ruel-Gariépy, E., Leclair, G., Hildgen, P., Gupta, A., \& Leroux, J.-C. (2002). Thermosensitive chitosan-based hydrogel containing liposomes for the delivery of hydrophilic molecules. Journal of Controlled Release, 82(2-3), 373-383. https://doi.org/10.1016/S0168-3659(02)00146-3

Saeedi Garakani, S., Davachi, S. M., Bagher, Z., Heraji Esfahani, A., Jenabi, N., Atoufi, Z., Khanmohammadi, M., Abbaspourrad, A., Rashedi, H., \& Jalessi, M. (2020). Fabrication of chitosan/polyvinylpyrrolidone hydrogel scaffolds containing PLGA microparticles loaded with dexamethasone for biomedical applications. International Journal of Biological Macromolecules, $\quad$ 164, $356-370$. https://doi.org/10.1016/j.ijbiomac.2020.07.138

Shariatinia, Z., \& Jalali, A. M. (2018). Chitosan-based hydrogels: Preparation, properties and applications. International Journal of Biological Macromolecules, 115, 194-220. https://doi.org/10.1016/j.ijbiomac.2018.04.034

Ta, H. T., Dass, C. R., \& Dunstan, D. E. (2008). Injectable chitosan hydrogels for localised cancer therapy. Journal of Controlled Release, 126(3), 205-216. https://doi.org/10.1016/j.jconrel.2007.11.018 
850 Ternullo, S., Schulte Werning, L. V., Holsæter, A. M., \& Škalko-Basnet, N. (2020). CurcuminIn-Deformable Liposomes-In-Chitosan-Hydrogel as a Novel Wound Dressing. Pharmaceutics, 12(1), 8. https://doi.org/10.3390/pharmaceutics12010008

Wang, K., \& Han, Z. (2017). Injectable hydrogels for ophthalmic applications. Journal of Controlled Release, 268, 212-224. https://doi.org/10.1016/j.jconrel.2017.10.031

Wei, L., Cai, C., Lin, J., \& Chen, T. (2009). Dual-drug delivery system based on hydrogel/micelle composites. Biomaterials, 30(13), 2606-2613. https://doi.org/10.1016/j.biomaterials.2009.01.006

Weiner, A. L., Carpenter-Green, S. S., Soehngen, E. C., Lenk, R. P., \& Popescu, M. C. (1985). Liposome-collagen gel matrix: A novel sustained drug delivery system. Journal of Pharmaceutical Sciences, 74(9), 922-925. https://doi.org/10.1002/jps.2600740903

Xing, L., Sun, J., Tan, H., Yuan, G., Li, J., Jia, Y., Xiong, D., Chen, G., Lai, J., Ling, Z., Chen, Y., \& Niu, X. (2019). Covalently polysaccharide-based alginate/chitosan hydrogel embedded alginate microspheres for BSA encapsulation and soft tissue engineering. International Journal of Biological Macromolecules, 127, 340-348. https://doi.org/10.1016/j.ijbiomac.2019.01.065

Yang, T.-T., Cheng, Y.-Z., Qin, M., Wang, Y.-H., Yu, H.-L., Wang, A.-L., \& Zhang, W.-F. (2017). Thermosensitive Chitosan Hydrogels Containing Polymeric Microspheres for Vaginal Drug Delivery. BioMed Research International, 2017, 1-12. https://doi.org/10.1155/2017/3564060

Yerushalmi, N., Arad, A., \& Margalit, R. (1994). Molecular and Cellular Studies of Hyaluronic Acid-Modified Liposomes as Bioadhesive Carriers for Topical Drug Delivery in Wound Healing. Archives of Biochemistry and Biophysics, 313(2), 267-273. https://doi.org/10.1006/abbi.1994.1387 
Zan, J., Zhu, D., Tan, F., Jiang, G., Lin, Y., \& Ding, F. (2006). Preparation of Thermosensitive Chitosan Formulations Containing 5-Fluorouracil/Poly-3-hydroxybutyrate Microparticles Used as Injectable Drug Delivery System. Chinese Journal of Chemical Engineering, 14(2), 235-241. https://doi.org/10.1016/S1004-9541(06)60064-5

Zhao, L., Zhu, L., Liu, F., Liu, C., Shan-Dan, Wang, Q., Zhang, C., Li, J., Liu, J., Qu, X., \& Yang, Z. (2011). PH triggered injectable amphiphilic hydrogel containing doxorubicin and paclitaxel. International Journal of Pharmaceutics, 410(1), 83-91. https://doi.org/10.1016/j.ijpharm.2011.03.034

Zhou, H. Y., Wang, Z. Y., Duan, X. Y., Jiang, L. J., Cao, P. P., Li, J. X., \& Li, J. B. (2016). Design and evaluation of chitosan- $\beta$-cyclodextrin based thermosensitive hydrogel. Biochemical Engineering Journal, 111, $100-107$. https://doi.org/10.1016/j.bej.2016.03.011

Zhu, S., Tian, H., Dou, M., \& Huang, G. (2018). Chitosan Temperature-Sensitive Gels: Reduce the Burst Release of Microspheres Containing Lornoxicam and Enhance Drug Targeting. MOJ Bioequiv Availab, 5(1), 00076. 